\title{
Effects of Volume Guaranteed Ventilation Combined with Two Different Modes in Preterm Infants
}

\author{
Sezin Unal MD, Ebru Ergenekon MD, Selma Aktas MD, Nilgun Altuntas MD, Serdar Beken MD, \\ Ebru Kazanci MD, Ferit Kulali MD, Ozlem Gulbahar MD, Ibrahim M Hirfanoglu MD, \\ Esra Onal MD, Canan Turkyilmaz MD, Esin Koc MD, and Yildiz Atalay MD
}

\begin{abstract}
BACKGROUND: Volume-controlled ventilation modes have been shown to reduce duration of mechanical ventilation, incidence of chronic lung disease, failure of primary mode of ventilation, hypocarbia, severe intraventricular hemorrhage, pneumothorax, and periventricular leukomalacia in preterm infants when compared with pressure limited ventilation modes. Volume-guarantee (VG) ventilation is the most commonly used mode for volume-controlled ventilation. Assist control, pressure-support ventilation (PSV), and synchronized intermittent mandatory ventilation (SIMV) can be combined with VG; however, there is a lack of knowledge on the superiority of each regarding clinical outcomes. Therefore, we investigated the effects of SIMV + VG and PSV + VG on ventilatory parameters, pulmonary inflammation, morbidity, and mortality in preterm infants. METHODS: Preterm infants who were born in our hospital between 24-32 weeks gestation and needed mechanical ventilation for respiratory distress syndrome were considered eligible. Patients requiring high-frequency oscillatory ventilation for primary treatment were excluded. Subjects were randomized to either SIMV + VG or PSV + VG. Continuously recorded ventilatory parameters, clinical data, blood gas values, and tracheal aspirate cytokine levels were analyzed. RESULTS: The study enrolled 42 subjects. Clinical data were similar between groups. PSV + VG delivered closer tidal volumes to set tidal volumes $(60 \%$ vs $49 \%, P=.02)$. Clinical data, including days on ventilation, morbidity, and mortality, were similar between groups. Chronic lung disease occurred less often and heart rate was lower in subjects who were ventilated with PSV + VG. The incidence of hypocarbia and hypercarbia were similar. Interleukin-1 $\beta$ in the tracheal aspirates increased during both modes. CONCLUSION: PSV + VG provided closer tidal volumes to the set value in ventilated preterm infants with respiratory distress syndrome and was not associated with overventilation or a difference in mortality or morbidity when compared to SIMV+VG. Therefore, PSV+VG is a safe mode of mechanical ventilation to be used for respiratory distress syndrome. Key words: mechanical ventilation; lung inflammation; preterm infants; tidal volume; ventilator-induced lung injury; dysplasia; bronchopulmonary. [Respir Care 2017;62(12):1525-1532. (C) 2017 Daedalus Enterprises]
\end{abstract}

Introduction

Volume-guarantee (VG) ventilation is one of the volume-controlled ventilation modes in which the ventilator automatically adjusts inspiratory pressure to achieve desired tidal volume $\left(\mathrm{V}_{\mathrm{T}}\right)$. Volume-controlled ventilation modes were shown to reduce duration of mechanical ventilation, incidence of chronic lung disease, failure of primary mode of ventilation, hypocarbia, grade 3/4 intraventricular hemorrhage, pneumothorax, and periventricular leukomalacia in preterm infants when compared with pressure-limited ventilation modes. ${ }^{1}$ It may be applied with pressure-support ventilation (PSV), assist-control ventilation, or synchronized intermittent mandatory ventilation (SIMV), although no data favors one over the other. ${ }^{2}$

To date, studies comparing synchronized modes with VG have been crossover studies and have reported that assist-control $+\mathrm{VG}$ or PSV $+\mathrm{VG}$ ventilation modes produced more stable $\mathrm{V}_{\mathrm{T}}$ compared to the $\mathrm{SIMV}+\mathrm{VG}$ mode during weaning without focusing on clinical morbidities. ${ }^{3-5}$ Nevertheless, it is not clear which ventilation mode should combine with VG. SIMV+VG supports a pre-set number of breaths with time-cycling, whereas PSV +VG supports each breath with flow-cycling method. The two specifica- 


\section{Volume Guarantee Ventilation in Preterm Infants}

tions of PSV, support of each breath and flow cycling, have been shown to produce shorter duration of mechanical ventilation and weaning, and work load, respectively, and thus may have an additive effect over VG when compared to SIMV + VG. ${ }^{6-9}$ However, overventilation due to support of each triggered breath is a potential risk that can result in hypocarbia and air leaks.

\section{See the Related Editorial on Page 1615}

We compared the ventilatory parameters, blood gases, and short- and long-term clinical outcomes together with pulmonary inflammation markers of preterm infants with respiratory distress syndrome who were ventilated with either PSV+VG or SIMV+VG.

\section{Methods}

This randomized, controlled trial was conducted between June 2011 and December 2013 (NCT01514331) in the Level III Neonatal Intensive Care Unit at the Gazi University Hospital, Ankara, Turkey. University Ethics Committee approved the study. Written informed consent was obtained from the parents.

\section{Study Design}

Preterm infants who were born in our hospital between 24-32 weeks gestation and needed mechanical ventilation treatment for respiratory distress syndrome in the first $12 \mathrm{~h}$ of life after surfactant treatment were considered eligible. Exclusion criteria were major congenital anomaly, pulmonary disease other than respiratory distress syndrome, ab-

Drs Unal, Ergenekon, Aktas, Altuntas, Beken, Kazanci, Kulali, Hirfanoglu, Onal, Turkyilmaz, Koc, and Atalay are affiliated with Gazi University Hospital, Department of Pediatrics, Division of Neonatology, Ankara, Turkey. Dr Unal is also affiliated with the Department of Neonatology, Etlik Zubeyde Hanım Women's Teaching and Research Hospital, Ankara, Turkey. Dr Gulbahar is affiliated with Gazi University Hospital, Department of Clinical Biochemistry, Ankara, Turkey.

Dr Unal presented a version of this paper as a poster at the 5th Congress of the European Academy of Paediatric Societies, held October 17-21, 2014, in Barcelona, Spain.

This study was funded by Gazi University Research Fund (Fund number: 01/2011-68)

\section{Clinical Trial Registration: NCT01514331}

Correspondence: Sezin Unal MD, Etlik Zubeyde Hanım Women's Health Teaching and Research Hospital Yeni-Etlik Caddesi, 06010 Etlik, Kecioren, Ankara, Turkey. E-mail: sezinunal@gmail.com

DOI: $10.4187 /$ respcare. 05513

\section{QUICK LOOK}

\section{Current knowledge}

Volume guarantee (VG) ventilation has proven positive clinical effects and can be combined with pressure support ventilation (PSV) and synchronized intermittent mandatory ventilation (SIMV). PSV + VG achieves more uniform tidal volumes during weaning when compared to SIMV+VG.

\section{What this paper contributes to our knowledge}

PSV + VG allowed for more breaths with closer tidal volume to the set value in mechanically ventilated preterm infants with respiratory distress syndrome and did not cause overventilation and hypocarbia. PSV + VG did not increase morbidity and mortality when compared to SIMV + VG. Similar pulmonary inflammation occurred in PSV +VG and SIMV + VG. PSV + VG is a safe and reasonable mode, and thus can be used more frequently for treatment of respiratory distress syndrome in preterm infants.

sence of spontaneous respiration, high-frequency oscillatory ventilation (HFOV) before conventional ventilation, and extubation within $6 \mathrm{~h}$. Our unit's indications for HFOV were pulmonary hypertension, air leak syndromes, and failure of conventional ventilation. The mechanical ventilation treatment was provided by Babylog 8000plus (Draeger, Lubeck, Germany). Subjects were randomized by a blinded neonatology fellow to either SIMV+VG or PSV + VG using sealed and sequentially numbered envelopes.

Baseline clinical characteristics including gestational age, birthweight, gender, mode of delivery, small for gestational age, Apgar score, surfactant treatment at delivery room, antenatal corticosteroid administration, preterm premature rupture of membranes, and clinical chorioamnionitis were recorded.

Ventilatory data, hemodynamic parameters, and blood gas analyses values were recorded for $72 \mathrm{~h}$ if extubation, mode change, or death did not occur earlier. Two tracheal aspirate (TA) samples were collected. The first samples (TA-1) were collected at $6 \mathrm{~h}$ after surfactant administration, and the second samples (TA-2) were collected at the time that data recording was stopped. Entire clinical morbidities were documented. Primary outcome was $V_{T}$ measurements during ventilation.

\section{Ventilatory Management and Data Transfer}

Initial ventilatory settings were: $\mathrm{V}_{\mathrm{T}}=4 \mathrm{~mL} / \mathrm{kg}$; PEEP, $5 \mathrm{~cm} \mathrm{H}_{2} \mathrm{O}$; and peak inspiratory pressure (PIP), 2-3 cm $\mathrm{H}_{2} \mathrm{O}$ higher than the minimum pressure to deliver target $\mathrm{V}_{\mathrm{T}}$; and $\mathrm{F}_{\mathrm{IO}_{2}}$ to maintain a saturation of $90-95 \%$ and trig- 


\section{Volume Guarantee Ventilation in Preterm Infants}

ger sensitivity, with a maximum sensitivity of 1 for both groups, on the basis of our clinical experience and accepted literature approaches. ${ }^{9}$ Target blood gas values were $\mathrm{pH}>7.20-7.25 ; \mathrm{P}_{\mathrm{aCO}_{2}} 45-55 \mathrm{~mm} \mathrm{Hg}$; and $\mathrm{P}_{\mathrm{aO}_{2}} 60-$ $80 \mathrm{~mm} \mathrm{Hg}$. The $\mathrm{V}_{\mathrm{T}}$ was increased to $6 \mathrm{~mL} / \mathrm{kg}$ when needed. In the SIMV + VG group, the breathing frequency was set as $40-60$ breaths/min, and inspiratory time was set at $0.30-0.36 \mathrm{~s}$. In the PSV+VG group, the breathing frequency was set as a back-up frequency of 40 breaths $/ \mathrm{min}$, and inspiratory time was limited to 1.5 times higher than the observed spontaneous inspiratory time (maximum, $0.60 \mathrm{~s}$ ). During the weaning process, trigger sensitivity for $\mathrm{PSV}+\mathrm{VG}$ and breathing frequency for SIMV + VG were adjusted besides set $\mathrm{V}_{\mathrm{T}}$ and $\mathrm{F}_{\mathrm{IO}_{2}}$ for both groups.

The set $\mathrm{V}_{\mathrm{T}}$, expiratory $\mathrm{V}_{\mathrm{T}}$, PIP set value, working PIP, mean airway pressure, minute ventilation, breathing frequency (set and measured), inspiratory time (set and measured), trigger sensitivity, air leak, and $\mathrm{F}_{\mathrm{IO}_{2}}$ were recorded every $10 \mathrm{~s}$ from the RS232 output port of the ventilator and were exported with Babyview1 software (Draeger) into a spreadsheet (Microsoft Excel, Microsoft, Redmond, WA).

Data cleaning was done according to the following criteria before analysis:

1. Breaths with leak $>40 \%$.

2. Breaths with unmeasured expiratory $\mathrm{V}_{\mathrm{T}}$, expiratory $\mathrm{V}_{\mathrm{T}}$ $<10 \%$ or $>200 \%$ of set $\mathrm{V}_{\mathrm{T}}$.

3. Working PIP $<$ PEEP.

4. $\mathrm{PEEP}<3 \mathrm{~cm} \mathrm{H}_{2} \mathrm{O}$.

5. Measured breathing frequency was 5 breaths/min or more below the set frequency and 20 breaths/min or more higher than the subject's frequency.

We calculated the ratio of expiratory $\mathrm{V}_{\mathrm{T}}$ to set $\mathrm{V}_{\mathrm{T}}$ in percentages for each recorded breath (expiratory $\mathrm{V}_{\mathrm{T}} / \mathrm{set}$ $\mathrm{V}_{\mathrm{T}} \times 100$ ). This value was categorized as appropriate expiratory $\mathrm{V}_{\mathrm{T}}$ if between $80 \%$ and $120 \%$, as low expiratory $\mathrm{V}_{\mathrm{T}}$ if $<80 \%$, and as high expiratory $\mathrm{V}_{\mathrm{T}}$ if $>120 \%$. The $\mathrm{V}_{\mathrm{T}}$ percentage value, working PIP, mean airway pressure, minute ventilation, and $\mathrm{F}_{\mathrm{IO}_{2}}$ were analyzed among groups after each parameter were averaged for each subject.

\section{Clinical Outcome Measures}

Respiratory Outcomes. HFOV requirement, repeated surfactant treatment, extubation failure (re-intubation due to abnormal blood gas with $\mathrm{F}_{\mathrm{IO}_{2}}>0.50$ or $\geq 2$ apneas needing positive-pressure ventilation or clinical respiratory distress), time to extubation, total days of mechanical ventilation, and noninvasive ventilation.
Hemodynamic Parameters and Blood Gas Analysis. Heart rate (beats/min), breathing frequency (breaths/min), mean arterial blood pressure ( $\mathrm{mm} \mathrm{Hg}$ ), $\mathrm{S}_{\mathrm{pO}_{2}}(\%)$ measurements, and $\mathrm{P}_{\mathrm{aO}_{2}}$ and $\mathrm{P}_{\mathrm{aCO}}$ were recorded manually. Incidences of hypocarbia $\left(\mathrm{P}_{\mathrm{aCO}_{2}}<30 \mathrm{~mm} \mathrm{Hg}\right)$, hypercarbia $\left(\mathrm{P}_{\mathrm{aCO}_{2}}>55 \mathrm{~mm} \mathrm{Hg}\right)$, hypoxemia $\left(\mathrm{P}_{\mathrm{aO}_{2}}<50 \mathrm{~mm} \mathrm{Hg}\right)$, and hyperoxemia $\left(\mathrm{P}_{\mathrm{aO}_{2}}>80 \mathrm{~mm} \mathrm{Hg}\right)$ were calculated as $n$ (of parameter $) / N($ total number of blood gas analysis $) \times 100$.

Morbidities and Mortality. Short-term morbidities included clinically important patent ductus arteriosus, pulmonary hemorrhage, pulmonary interstitial emphysema, intraventricular hemorrhage ( $\geq$ grade 3 ). Long-term morbidities included retinopathy of prematurity ( $\geq$ stage 2 ), necrotizing enterocolitis, periventicular leukomalacia, chronic lung disease (oxygen dependence at 36th weeks), and sepsis. Mortality was death in unit before discharge.

TA Collection and Cytokine Analysis. Two samples (TA-1 and TA-2) were collected. The TA-1 samples were collected at $6 \mathrm{~h}$ after surfactant administration. The TA-2 were collected at $72 \mathrm{~h}$ if extubation, mode change, or death did not occur earlier. TA samples were obtained after introducing $1 \mathrm{~mL} / \mathrm{kg}$ saline into trachea. After being centrifuged (10 $\mathrm{min}$ at 3,600 revolutions/min), supernatants were stored at $-80^{\circ} \mathrm{C}$ until analyzed for 4 interleukins (IL- $\beta$, IL-6, IL-8, and IL-10). Interleukins were measured with the enzyme-linked immunosorbent assay method (eBioscience, Bender MedSystems GmbH, Vienna, Austria). Interleukin levels were presented as $\mathrm{pg} / \mathrm{mg}$-protein (TA protein; Quantichrom Protein Assay Kit, BioAssay Systems, Hayward, CA).

\section{Statistical Analysis}

Statistical analysis was performed using SPSS, version 15.0 (SPSS, Chicago, IL). A $P$ value $<.05$ was considered statistically significant. Numerical variables were expressed as median (interquartile range [IQR]) and analyzed with the Mann-Whitney $U$ test. Categorical variables were expressed as numbers $n / N(\%)$ and analyzed using the chi-square test. The Wilcoxon test was performed for paired measurements of TA-IL. The main outcome was percentage of expiratory $\mathrm{V}_{\mathrm{T}}$ in the appropriate range. The assist-control+VG was shown to cause $50 \%$ more breaths within the target $\mathrm{V}_{\mathrm{T}}$ range compared to assist-control. ${ }^{10}$ Based on that, power analysis revealed 16 subjects in each group to detect a $25 \%$ difference between the ratio of $\mathrm{V}_{\mathrm{T}}$ within the target range between the 2 modes with $80 \%$ power and $\alpha$ of 0.05 .

\section{Results}

We assessed 158 patients (24-32 weeks gestation) for eligibility. Forty-two subjects were enrolled, divided evenly 


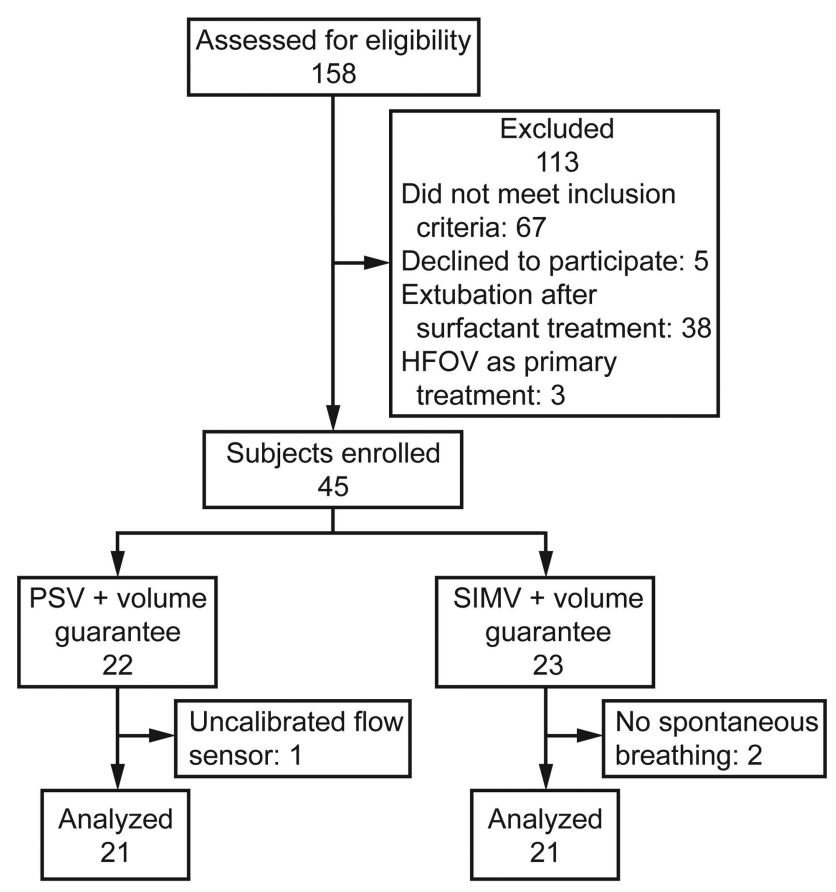

Fig. 1. Flow chart. HFOV = high-frequency oscillatory ventilation, PSV = pressure-support ventilation, SIMV = synchronized intermittent mandatory ventilation.

between the two study groups (subjects with birthweight $\leq 1,000 \mathrm{~g}: \mathrm{PSV}+\mathrm{VG}, n=17$; SIMV +VG; $n=15$ ), and completed the study as shown in Figure 1. Baseline clinical characteristics were similar among groups (Table 1).

Ventilatory data, hemodynamic parameters, and blood gas analyses were evaluated for $42 \mathrm{~h}$ (IQR, 25-72) in the $\mathrm{PSV}+\mathrm{VG}$ group and $52 \mathrm{~h}$ (IQR, 24-72) in the SIMV+ VG group $(P=.93)$.

\section{Ventilatory Parameters}

Data of 511,171 breaths were analyzed (PSV+VG: 240,658 breaths; SIMV+VG: 270,513 breaths). Percentage of excluded breaths (9\% [IQR, 7-11\%] and 10\% [IQR, $8-11 \%$ ], $P=.20$ ), leak (5\% [IQR, 2-7\%] and 4\% [IQR, $1-6 \%$ ]; $P=.38)$, and set $\mathrm{V}_{\mathrm{T}}(4.1 \mathrm{~mL} / \mathrm{kg}$ [IQR, $4.0-$ $4.5 \mathrm{~mL} / \mathrm{kg}$ ] and $4.2 \mathrm{~mL} / \mathrm{kg}$ [IQR, $4.0-4.8 \mathrm{~mL} / \mathrm{kg}$ ], $P=.64$ ) were comparable between the PSV $+\mathrm{VG}$ and SIMV $+\mathrm{VG}$ groups, respectively.

Infants in the PSV +VG group produced more breaths with appropriate $\mathrm{V}_{\mathrm{T}}$ and fewer breaths with low $\mathrm{V}_{\mathrm{T}}$ as shown in Figure 2. However, working PIP, mean airway pressure, minute ventilation, and $\mathrm{F}_{\mathrm{IO}_{2}}$ remained similar between groups as summarized in Table 2 .

\section{Clinical Outcomes}

Entire clinical outcome measures are shown in Table 3. Four subjects in the SIMV+VG group died, and 2 subjects in the PSV+VG group died. Respiratory outcomes and morbidities were similar between groups. Three subjects in the PSV $+\mathrm{VG}$ group and 5 subjects in the SIMV $+\mathrm{VG}$ group required rescue HFOV treatment. No pneumothorax was observed. Chronic lung disease was observed less frequently in the PSV + VG group, although the difference was not statistically significant. None of the subjects with chronic lung disease received steroid treatment.

\section{Hemodynamic Parameters and Blood Gas Analyses}

Infants in the PSV + VG group had a slower heart rate than infants on SIMV + VG during the study period. Total blood gas analyses were 245 in the PSV + VG group and 230 in the SIMV +VG group. The number of analyses per subject [mean (IQR)] in the PSV+VG and SIMV+VG groups were $9(6-15)$ and 8 (5-18), respectively. Hypocarbia occurred less frequently in the PSV $+\mathrm{VG}$ group (9\%) than in the SIMV+VG group (20\%), although the difference was not statistically different. Hypercarbia, hypoxia, and hyperoxia were observed to be similar between the 2 groups.

\section{TA Cytokine Analyses}

Of the 69 collected aspirates, 23 paired samples were sufficient for IL measurement (PSV+VG, 12; SIMV + VG, 11) due to failure to obtain supernatant. All TA-1 samplings were performed at $6 \mathrm{~h}$, and median TA-2 sampling time was at $43 \mathrm{~h}$ (IQR, 32-72) in PSV $+\mathrm{VG}$ group and at $47 \mathrm{~h}(24-72)$ in the SIMV + VG group $(P=.83)$. The IL-1 $\beta$, IL-6, IL-8, and IL-10 levels were similar between both groups in TA- 1 and TA- 2 samples. IL- $1 \beta$ increased significantly in both groups. The IL-8 levels tended to rise in both groups, but the difference was statistically significant only in the PSV+VG group. The IL-6 and IL-10 levels remained stable. The TA-IL levels among groups are shown in Figure 3.

\section{Discussion}

In this study, we compared PSV + VG and SIMV + VG modes with regard to ventilation parameters, hemodynamic effects, blood gas values, clinical outcomes, and inflammatory responses. We observed that PSV $+\mathrm{VG}$ provided more appropriate expiratory $\mathrm{V}_{\mathrm{T}}$ values during the ventilation period compared to SIMV $+\mathrm{VG}$, with no increase in adverse clinical effects.

It is hard to evaluate studies in the literature that compare different mechanical ventilation treatments because each treatment might differ from the other by more than one feature. The PSV+VG mode was most frequently compared to SIMV and was found to cause less postextubation atelectasis and required less blood gas analysis, 
Table 1. Clinical Characteristics of Study Subjects

\begin{tabular}{|c|c|c|c|}
\hline & $\mathrm{PSV}+\mathrm{VG} n=21$ & SIMV+VG $n=21$ & $P$ \\
\hline Gestational age, weeks mean (IQR) & $29(27-31)$ & $28(25-31)$ & .75 \\
\hline Birth weight, g & $980(810-1422)$ & $870(702-1,700)$ & .72 \\
\hline Male, $n(\%)$ & $8(38)$ & $9(43)$ & $>.99$ \\
\hline Cesarean section, $n(\%)$ & $18(82)$ & $15(71)$ & .45 \\
\hline Small for gestational age, $n(\%)$ & $4(20)$ & $3(14)$ & $>.99$ \\
\hline Apgar score $<7$ at $5 \min , n(\%)$ & $2(10)$ & $5(24)$ & .21 \\
\hline Surfactant treatment in delivery room, $n(\%)$ & $9(43)$ & $10(48)$ & $>.99$ \\
\hline Antenatal corticosteroid, $n(\%)$ & $13(62)$ & $8(38)$ & .12 \\
\hline Preterm premature rupture of membranes, $n(\%)$ & $6(29)$ & $2(10)$ & .24 \\
\hline Chorioamnionitis, $n(\%)$ & $8(39)$ & $3(14)$ & .08 \\
\hline Late neonatal sepsis, $n(\%)$ & $9(52)$ & $8(47)$ & .86 \\
\hline $\begin{array}{l}\text { PSV }=\text { pressure support ventilation } \\
\text { SIMV = synchronized intermittent mandatory ventilation } \\
\text { VG = volume guarantee } \\
\text { IQR = interquartile range }\end{array}$ & & & \\
\hline
\end{tabular}

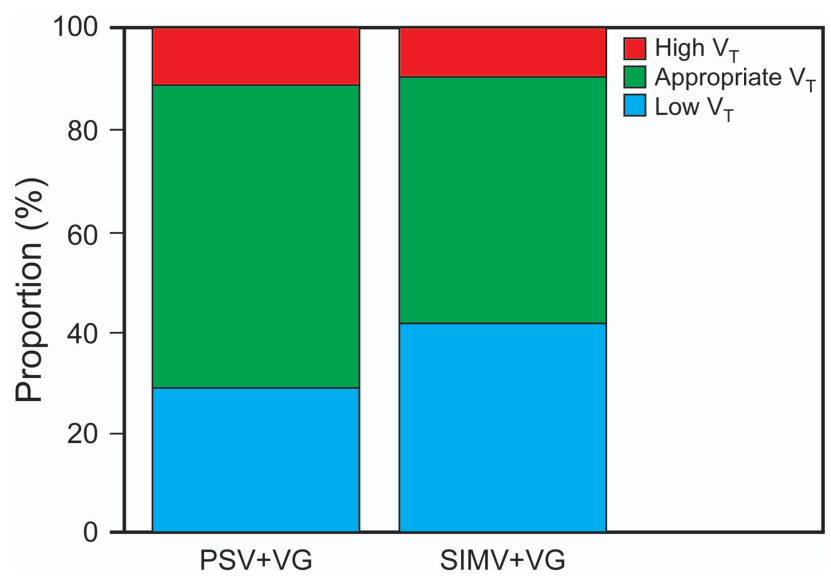

Fig. 2. Distribution of categorized tidal volume percentages of subjects in SIMV + volume guarantee and PSV+ volume guarantee groups (appropriate, low, and high $\mathrm{V}_{\mathrm{T}}$ ) during the data recording period. Values refer to medians. Appropriate $\mathrm{V}_{\mathrm{T}} ; P=.02$, Low $\mathrm{V}_{\mathrm{T}}$; $P=.01$. High $\mathrm{V}_{\mathrm{T}}$ is $>120 \%$ of set $\mathrm{V}_{\mathrm{T}}$, appropriate $\mathrm{V}_{\mathrm{T}}=80-120 \%$ of set $\mathrm{V}_{\mathrm{T}}$, and low $\mathrm{V}_{\mathrm{T}}$ is $<80 \%$ of set $\mathrm{V}_{\mathrm{T}}$.

whereas assessment of respiratory mechanics revealed conflicting results. ${ }^{1-14}$ However, these two modes are different from each other with regard to cycling (flow/time), control measure (volume/pressure), and supported number of breaths (all triggered/pre-set number).

Three previous short-term crossover trials assessed these 2 modes in stable preterm infants during weaning. ${ }^{3-5}$ Therefore, we compared PSV + VG to SIMV + VG in terms of clinical outcomes and pulmonary inflammation, in addition to ventilatory data monitored for longer periods of time. We found more appropriate $V_{T}$ values were delivered during PSV $+V G$ than SIMV $+V G$. Because $\mathrm{PSV}+\mathrm{VG}$ supports every triggered breath, whereas SIMV + VG supports only a set number of breaths, which affects the number of volume-guaranteed breaths, unsupported breaths therefore have $\mathrm{V}_{\mathrm{T}}$ values lower than the targeted range. In our study, higher minute ventilation was produced during PSV $+\mathrm{VG}$ ventilation than during SIMV + VG ventilation, possibly due to the delivery of more appropriate $\mathrm{V}_{\mathrm{T}}$ values, although the difference was not statistically significant. Short-term crossover trials reported working PIP, breathing frequency, and minute ventilation similar to our findings, while mean airway pressure results were inconsistent between PSV+VG and SIMV + VG. In our study, we observed that mean airway pressure was similar between groups. ${ }^{4-5}$ These conflicting results show the importance of individual variances and the difficulty of assessment of ventilatory parameters. We observed lower heart rate in PSV $+\mathrm{VG}$ group compared to SIMV + VG group, which is in line with the results of Abubakar and Keszler. ${ }^{3}$ Lower heart rate might be the result of total synchrony of patient with the ventilator, which is a feature of flow cycling. ${ }^{7}$ Hypocarbia, hypercarbia, and hyperoxia have been shown to contribute to the development of periventricular leukomalacia, hemorrhage, and retinopathy of prematurity, respectively. ${ }^{15-19}$ Lowest or highest arterial carbon dioxide or oxygen levels did not differ in either mode, making each equally reliable with regard to prevention of extreme values. Our weaning strategy in PSV+VG was based on decreasing trigger sensitivity, which may have contributed to the prevention of hypocarbia during PSV +VG. As trigger sensitivity is decreased, the number of breaths exceeding threshold would decrease, thus decreasing the number of supported breaths. The requirement for HFOV and the need for repeated surfactant treatment, incidence of patent ductus arteriosus, time to extubation, extubation failure, days of mechanical ventilation, and noninvasive ventilation were similar in 
Table 2. Ventilatory Parameters During PSV + VG and SIMV+VG Ventilation

\begin{tabular}{|c|c|c|c|}
\hline & $\mathrm{PSV}+\mathrm{VG} n=21$ & SIMV+VG $n=21$ & $P$ \\
\hline Set $\mathrm{V}_{\mathrm{T}}, \mathrm{mL} / \mathrm{kg}(\mathrm{IQR})$ & $4.1(4.0-4.5)$ & $4.2(4.0-4.8)$ & .64 \\
\hline Working PIP, $\mathrm{cm} \mathrm{H}_{2} \mathrm{O}$ (IQR) & $17.5(14.9-19.6)$ & $17.3(15.1-20.0)$ & .89 \\
\hline Mean airway pressure, $\mathrm{cm}_{2} \mathrm{O}$ (IQR) & $7.7(6.7-8.3)$ & $7.0(6.4-7.5)$ & .24 \\
\hline Minute ventilation, $\mathrm{mL} / \mathrm{min}(\mathrm{IQR})$ & $254(195-332)$ & $212(158-321)$ & .25 \\
\hline $\mathrm{F}_{\mathrm{IO}_{2}},(\mathrm{IQR})$ & $0.29(0.25-0.34)$ & $0.28(0.23-0.37)$ & .94 \\
\hline $\begin{array}{l}\text { PSV }=\text { pressure support ventilation } \\
\text { SIMV = synchronized intermittent mandatory ventilat } \\
\text { VG }=\text { volume guarantee } \\
\text { IQR = interquartile range }\end{array}$ & & & \\
\hline
\end{tabular}

Table 3. Respiratory Outcome, Important Morbidities, Hemodynamic Parameters, and Blood Gas Analysis Results

\begin{tabular}{|c|c|c|c|}
\hline & $\mathrm{PSV}+\mathrm{VG} n=21$ & $\mathrm{SIMV}+\mathrm{VG} n=21$ & $P$ \\
\hline \multicolumn{4}{|c|}{ Respiratory treatment outcome (among patients without high-frequency oscillatory ventilation) } \\
\hline Repeated surfactant treatment & $9 / 18(50)$ & $5 / 16(36)$ & .43 \\
\hline Extubation failure & $4 / 18(22)$ & $7 / 16(50)$ & $>.99$ \\
\hline Time to extubation, $\mathrm{h}$ (IQR) & $33(24-115)$ & $58(30-213)$ & .41 \\
\hline Time on mechanical ventilation in NICU, d (IQR) & $4(1-14)$ & $2.5(2-15)$ & .95 \\
\hline Time on noninvasive ventilation in NICU, $\mathrm{d}$ (IQR) & $17(5-32)$ & $20(3-40)$ & .88 \\
\hline \multicolumn{4}{|l|}{ Short-term morbidities } \\
\hline Patent ductus arteriosus (requiring treatment) & $13 / 21(62)$ & $10 / 21(50)$ & .65 \\
\hline Pulmonary hemorrhage & $2 / 21(10)$ & $3 / 21(14)$ & $>.99$ \\
\hline Pulmonary interstitial emphysema & $2 / 21(10)$ & $2 / 21(10)$ & $>.99$ \\
\hline Intraventricular hemorrhage (Papile grade 3 or 4 ) & $2 / 21(10)$ & $2 / 21(10)$ & $>.99$ \\
\hline \multicolumn{4}{|c|}{ Long-term morbidities (among patients without high-frequency oscillatory ventilation) } \\
\hline Retinopathy of prematurity ( $\geq$ Stage 2 ) & $3 / 16(19)$ & 4/14 (29) & .68 \\
\hline Necrotizing enterocolitis ( $\geq$ Stage 2 ) & $4 / 17(23)$ & $3 / 14(21)$ & $>.99$ \\
\hline Periventricular leukomalacia & $2 / 17(12)$ & $2 / 14(14)$ & $>.99$ \\
\hline Chronic lung disease among all survivors & $6 / 19(32)$ & $7 / 17(42)$ & .55 \\
\hline \multicolumn{4}{|l|}{ Hemodynamic parameters and blood gas analyses } \\
\hline Breathing frequency, breaths/min (IQR) & $69(56-78)$ & $65(55-80)$ & .89 \\
\hline Heart rate, beats/min (IQR) & $145(138-153)$ & $154(144-162)$ & .02 \\
\hline $\mathrm{S}_{\mathrm{pO}_{2}}, \%(\mathrm{IQR})$ & $92(92-95)$ & $92(91-97)$ & .49 \\
\hline Mean arterial tension, $\mathrm{mm} \mathrm{Hg}$ (IQR) & $37(34-40)$ & $36(31-38)$ & .13 \\
\hline Hypocarbia incidence, \% (IQR) & $5(0-20)$ & $9(0-31)$ & .56 \\
\hline Hypercarbia incidence, \% (IQR) & $0(0-10)$ & $0(0-4)$ & .60 \\
\hline Hypoxemia incidence, \% (IQR) & $12(0-28)$ & $0(0-17)$ & .14 \\
\hline Hyperoxemia incidence, \% (IQR) & $14(4-49)$ & $22(10-50)$ & .51 \\
\hline $\begin{array}{l}\text { PSV }=\text { pressure support ventilation } \\
\text { SIMV = synchronized intermittent mandatory ventilation } \\
\text { VG = volume guarantee } \\
\text { IQR = interquartile range } \\
\text { NICU = neonatal ICU }\end{array}$ & & & \\
\hline
\end{tabular}

both groups. It is worth noting that the high antenatal steroid rate in PSV $+\mathrm{VG}$ group, although not statistically significant, may have affected the severity of respiratory distress and masked probable differences in terms of ventilatory effectiveness.

Ventilation-induced lung injury is an important complication of mechanical ventilation, and cytokine response in TA of ventilated newborns has been considered as its bio- marker. ${ }^{20}$ We observed elevation of IL- $1 \beta$ levels over time in both groups, supporting previous findings that conventional ventilation increases IL- $1 \beta$ levels. ${ }^{21}$ Most studies compared pulmonary inflammation either to evaluate effects of HFOV or VG ventilation. ${ }^{21-23}$ In the limited number of TA samples tested in our study, there was no substantial differences between cytokines with either VG ventilation method. 


\section{Volume Guarantee Ventilation in Preterm Infants}
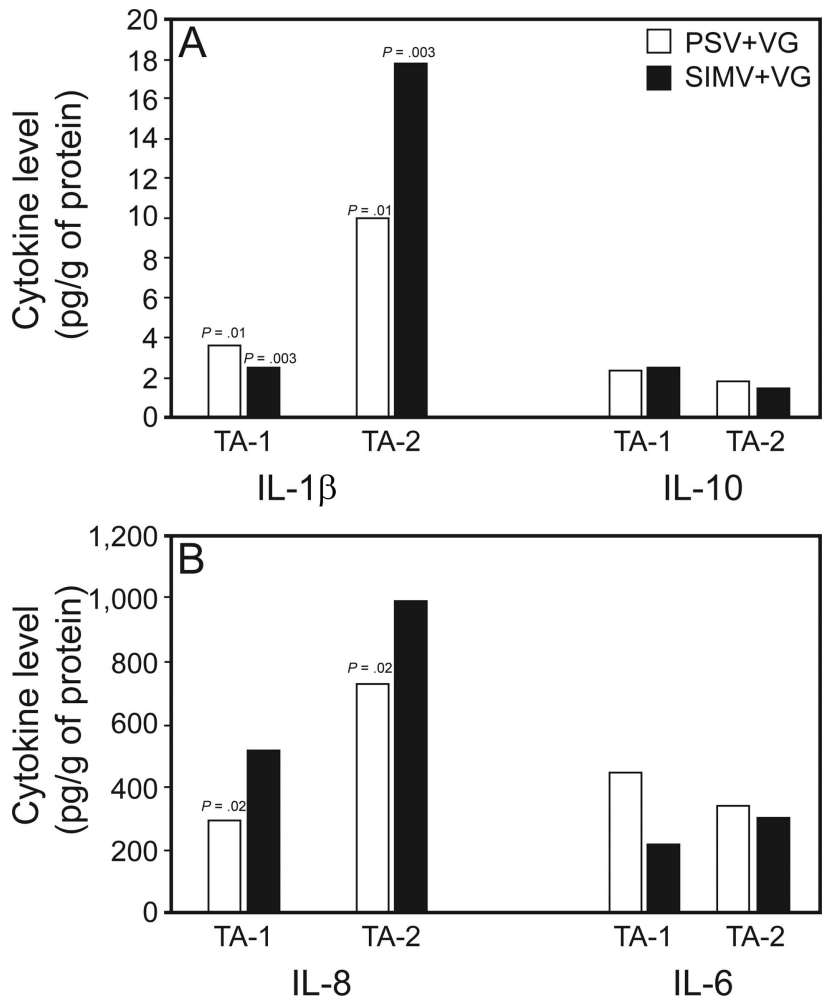

Fig. 3. Cytokine levels in tracheal aspirates. Bars show medians. Wilcoxon test for paired measurements of interleukin levels in tracheal aspirates were statistically significant for IL-1 $\beta(P=.01)$ and $\mathrm{IL}-8(P=.02)$ in PSV + volume guarantee group, and IL-1 $\beta(P=$ $.003)$ in SIMV + volume guarantee group.

The major feature of our study is that we reported clinical outcomes regarding PSV + VG or SIMV + VG ventilation. Evaluation of ventilatory parameters during a long period of ventilation is another positive aspect. A major limitation of our study is the small sample size, which was due to increased use of noninvasive ventilation as our institution's respiratory support strategy. Although we have been able to document the $\mathrm{V}_{\mathrm{T}}$ difference between groups, our study is not powered enough to document the difference in mortality and incidence of clinical outcomes including chronic lung disease. Likewise, different antenatal steroid administration ratios in the groups might have influenced respiratory outcomes. Furthermore, insufficient paired TA samples restricted the assessment of inflammation.

\section{Conclusions}

Our study supports the finding that PSV + VG allows for more stabilized breaths by providing more appropriate $\mathrm{V}_{\mathrm{T}}$ in ventilated preterm infants with respiratory distress syndrome. However, breathing frequency and minute ventilation were similar between groups, while heart rate was lower in the PSV+VG group. Overventilation with hypocarbia or hyperoxia were similar between the groups. Chronic lung disease occurred less with PSV + VG but difference was not statistically significant. While our results could not be generalized regarding the limitations we discussed, we can suggest that PSV + VG is a safe mode to be used for treatment of respiratory distress syndrome in preterm infants. Further studies investigating the clinical outcomes of different ventilation methods with VG involving larger populations are warranted.

\section{ACKNOWLedgments}

We would like to thank to Nuray Duman, Professor of Pediatrics (Dokuz Eylül University, Division of Neonatology) for providing the Babyview1 program.

\section{REFERENCES}

1. Peng W, Zhu H, Shi H, Liu E. Volume-targeted ventilation is more suitable than pressure-limited ventilation for preterm infants: a systematic review and meta-analysis. Arch Dis Child Fetal Neonatal Ed 2014;99(2):F158-F165

2. Ahluwalia JS, Morley CJ, Wahle H. Volume guarantee: new approaches in volume-controlled ventilation for neonates. Lubeck, Germany: Draegerwerk AG \& Co. KGaA: 2015. http://www.draeger. com/Library/Content/rsp_volume_guarantee_booklet_9097501_en.pdf. Accessed February 11, 2017.

3. Abubakar K, Keszler M. Effect of volume guarantee combined with assist/control vs synchronized intermittent mandatory ventilation. J Perinatol 2005;25(10):638-642.

4. Abubakar KM, Keszler M. Patient-ventilator interactions in new modes of patient-triggered ventilation. Pediatr Pulmonol 2001;32(1): 71-75.

5. Scopesi F, Calevo MG, Rolfe P, Arioni C, Traggiai C, Risso FM, Serra G. Volume targeted ventilation (volume guarantee) in the weaning phase of premature newborn infants. Pediatr Pulmonol 2007; 42(10):864-870.

6. Greenough A, Murthy V, Milner AD, Rossor TE, Sundaresan A. Synchronized mechanical ventilation for respiratory support in newborn infants. Cochrane Database Syst Rev 2016;(8):CD000456.

7. De Luca D, Conti G, Piastra M, Paolillo PM. Flow-cycled versus time-cycled sIPPV in preterm babies with RDS: a breath-to-breath randomised cross-over trial. Arch Dis Child Fetal Neonatal Ed 2009; 94(6):F397-F401

8. Kapasi M, Fujino Y, Kirmse M, Catlin EA, Kacmarek RM. Effort and work of breathing in neonates during assisted patient-triggered ventilation. Pediatr Crit Care Med 2001;2(1):9-16.

9. Schulzke SM, Pillow J, Ewald B, Patole SK. Flow-cycled versus time-cycled synchronized ventilation for neonates. Cochrane Database Syst Rev 2010;(7):CD008246.

10. Keszler M, Abubakar K. Volume guarantee: stability of tidal volume and incidence of hypocarbia. Pediatr Pulmonol 2004;38(3):240-245.

11. Abd El-Moneim ES, Fuerste HO, Krueger M, Elmagd AA, Brandis M, Schulte-Moenting J, Hentschel R. Pressure support ventilation combined with volume guarantee versus synchronized intermittent mandatory ventilation: a pilot crossover trial in premature infants in their weaning phase. Pediatr Crit Care Med 2005;6(3):286-292.

12. Erdemir A, Kahramaner Z, Turkoglu E, Cosar H, Sutcuoglu S, Ozer EA. Effects of synchronized intermittent mandatory ventilation versus pressure support plus volume guarantee ventilation in the wean- 


\section{Volume Guarantee Ventilation in Preterm Infants}

ing phase of preterm infants. Pediatr Crit Care Med 2014;15(3):236241.

13. Nafday SM, Green RS, Lin J, Brion LP, Ochshorn I, Holzman IR. Is there an advantage of using pressure support ventilation with volume guarantee in the initial management of premature infants with respiratory distress syndrome? A pilot study. J Perinatol 2005;25(3):193197.

14. Olsen SL, Thibeault DW, Truog WE. Crossover trial comparing pressure support with synchronized intermittent mandatory ventilation. J Perinatol 2002;22(6):461-466.

15. Okumura A, Hayakawa F, Kato T, Itomi K. Maruyama K, Ishihara $\mathrm{N}$ et al. Hypocarbia in preterm infants with periventricular leukomalacia: the relation between hypocarbia and mechanical ventilation Pediatrics 2001;107(3):469-475.

16. Erickson SJ, Grauaug A, Gurrin L, Swaminathan M. Hypocarbia in the ventilated preterm infant and its effect on intraventricular haemorrhage and bronchopulmonary dysplasia. J Paediatr Child Health 2002;38(6):560-562.

17. Jankov RP, Tanswell AK. Hypercapnia and the neonate. Acta Paediatr 2008;97(11):1502-1509.

18. Shankaran S, Langer JC, Kazzi SN, Laptook AR, Walsh M. Cumulative index of exposure to hypocarbia and hyperoxia as risk factors for periventricular leukomalacia in low birth weight infants. Pediatrics 2006;118(4):1654-1659.

19. Thome UH, Carroll W, Wu TJ, Johnson RB, Roane C, Young D, Carlo WA. Outcome of extremely preterm infants randomized at birth to different $\mathrm{PaCO} 2$ targets during the first seven days of life. Biol Neonate 2006;90(4):218-225

20. Clark RH, Gerstmann DR, Jobe AH, Moffitt ST, Slutsky AS, Yoder BA. Lung injury in neonates: causes, strategies for prevention, and long-term consequences. J Pediatr 2001;139(4):478-486.

21. Dani C, Bertini G, Pezzati M, Filippi L, Pratesi S, Caviglioli C, Rubaltelli FF. Effects of pressure support ventilation plus volume guarantee vs. high-frequency oscillatory ventilation on lung inflammation in preterm infants. Pediatr Pulmonol 2006;41(3):242-249.

22. Lista G, Castoldi F, Bianchi S, Battaglioli M, Cavigioli F, Bosoni MA. Volume guarantee versus high-frequency ventilation: lung inflammation in preterm infants. Arch Dis Child Fetal Neonatal Ed 2008;93(4):F252-F256.

23. Lista G, Colnaghi M, Castoldi F, Condo V, Reali R, Compagnoni G, Mosca F. Impact of targeted-volume ventilation on lung inflammatory response in preterm infants with respiratory distress syndrome (RDS). Pediatr Pulmonol 2004;37(6):510-514.

This article is approved for Continuing Respiratory Care Education credit. For information and to obtain your CRCE

(free to AARC members) visit

www.rcjournal.com 